\title{
Schwannoma of the Superficial Peroneal Nerve in 12-Year-Old Female Child: A Case Report
}

\author{
Siddaram N. Patil, K. B. Dinesh Babu, Sandeep Reddy, Divya Bandari, \\ Gannerla Sudhaker, V. Pranavi \\ Mamata Medical College, Mamata General \& Superspeciality Hospital, Khammam, India \\ Email: snpatil50@hotmail.com
}

Received 24 May 2014; revised 8 July 2014; accepted 23 July 2014

Copyright (C) 2014 by authors and Scientific Research Publishing Inc. This work is licensed under the Creative Commons Attribution International License (CC BY). http://creativecommons.org/licenses/by/4.0/

\section{(c) (i) Open Access}

\begin{abstract}
We present a case of Schwannoma of superficial peroneal nerve that presents as single enlarging mass in anterolateral aspect of right leg. After clinical diagnosis work-up is done with ultrasound, MRI and excision biopsy.
\end{abstract}

\section{Keywords}

Nerve Sheath, Superficial Peronial Nerve, Schwannoma, Neurilemmomas

\section{Introduction}

Schwannomas (or neurilemmomas) are, lobulated, encapsulated tumours that arise from the neurilemmal cells in nerve sheaths [1]. They usually arise in peripheral nerves or nerve roots. They may occur singly or in multiple, and have been found in a number of locations. They are normally benign, however they can rarely be malignant [2].

However in some patients they can be related to a hereditary disorder. Schwannomas can be found in various parts of the body with the most common site being the head. In the extremities they are most commonly found in the deep tissues of the foot [3]. Schwannoma of the superficial peroneal nerve is very rare [4]-[6]. Peripheral nerve sheath tumours: Three main histological types can be distinguished. Schwannoma (also known as neurilemmoma) and the neurofibroma are the benign forms. The malignant counterpart is the malignant peripheral nerve sheath tumour (MPNST).

Schwannomas are slow-growing encapsulated tumours that can be separated surgically from the parent nerve. Occasionally in large or long-standing schwannomas intralesional degeneration with fibrosis, haemorrhage, cal- 
cification and cystic necrosis occurs, leading to a so-called ancient schwannoma [7] [8]. In case of an elongated cystic mass along the peroneal nerve, an intraneural ganglion is a more likely diagnosis [8].

Histologically these tumours are composed of different areas composed of different cellular densities. More cellular areas (Antoni A) are composed of a haphazard arrangement of bland cells with spindled and oval nuclei. Loose, less cellular areas (Antoni B) are composed of a loose oedematous and mucinous stroma with fibrillar collagen.

\section{Case Report}

A 12-year-old female patient presented to us with complaints of swelling over the anterolateral aspect of right leg lower third region since 1 year (Figure 1). Swelling was insidious in onset, initial size being that of pea nut which gradually progressed to about $5 \times 3 \times 2 \mathrm{~cm}$ at the time of presentation. Patient did not give any history of trauma/prick injury. Patient gives history of previous unsuccessful attempt at excising this mass has been made 3months back. No history of constitutional symptoms and any other similar swellings in the body. On examination proper, swelling extended from the $3 \mathrm{~cm}$ from tip of lateral malleolus to $8 \mathrm{~cm}$ from lateral malleolus. Swelling was ovoid in shape with Small wound over anterior aspect of swelling with serous discharge. Swelling was firm in consistency with mild tenderness and no local rise of temperature. It was non-reducible and non-translucent, immobile in both horizontal and vertical direction. Sensations are diminished over dorsum of right foot. No motor weakness present. Movements at right ankle joint are normal.

X-ray revealed well defines lesion in the soft tissue with erosion of underlying bone (Figure 2) Serum calcium and serum phosphorus was $10.2 \mathrm{mg} / \mathrm{dl}$ and $3.0 \mathrm{mg} / \mathrm{dl}$ respectively. Serum ALP (127 IU/l), parathyroid

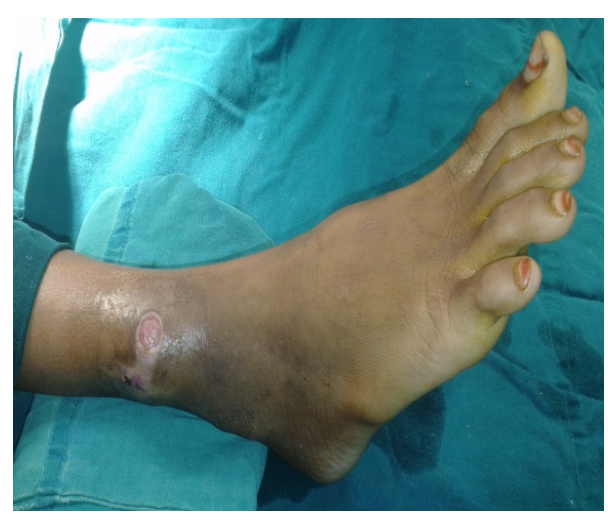

Figure 1. Clinical Picture of swelling on anterolateral aspect of lower third of leg.

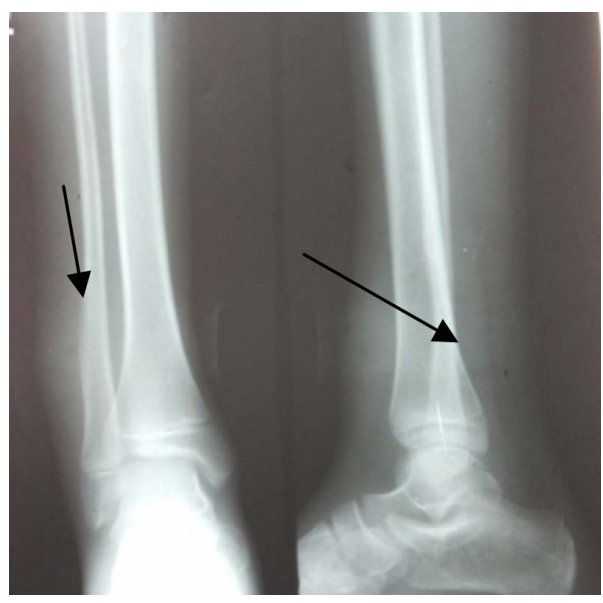

Figure 2. Fibula showing erosion of the lateral cortex. 
hormone levels, creatinine kinase, aldolase levels, ANA, Vitamin D levels, 24 hours urinary calcium and inorganic phosphate were all within normal limits. Ultrasound of the swelling confirmed large well defined multiple lobulated, hypoechoeic lesion with few echogenic areas and fibrous septa in it. MRI of the lower third leg with ankle was done which revealed mulitlobulated, multiseptated soft tissue lesion in the lower aspect of anterolateral muscle compartment of right leg (Figure 3), suggestive of schwannoma and hence excision biopsy was planned for confirmative diagnosis and definitive treatment.

Gross examination of the biopsy specimen revealed grayish white bits measuring $4 \times 3 \times 2 \mathrm{~cm}$, along with multiple tiny bits altogether measuring $2 \times 1 \times 1 \mathrm{~cm}$. cut section shows homogenous grey white nodular areas (Figure 4).

Microscopic examination smear showed Antoni A area is composed of spindle shaped Schwann cells arranged in interlacing fascicles without any hemorrhage and necrosis (Figure 5(a), Figure 5(b)).

\section{Discussion}

A schwannoma of the superficial peroneal nerve is very rare. There were no available data on the incidence of this occurrence.

The first report [2] describes a patient presenting with pain at his right fourth toe and at his dorsal fourth web space. This pain was worsened when pressure was applied at the mid-calf region. On surgical exploration, and subsequent histological investigation, a benign schwannoma of the deep peroneal nerve was found. Post-operatively his symptoms had completely abated.

The second report [3] describes a patient who had presented with an 8-year history of paraesthesia on the dorsal aspect of her right foot, and a mass in the lateral aspect of her popliteal fossa. A 30-cm long tumour was excised from the lateral peroneal nerve. Subsequently the patient developed a right sided foot drop, and paraesthesia anterior and lateral on the right lower leg.

Schwannomas are lobulated, encapsulated tumours that arise from the neurilemmal cells in nerve sheaths [3].
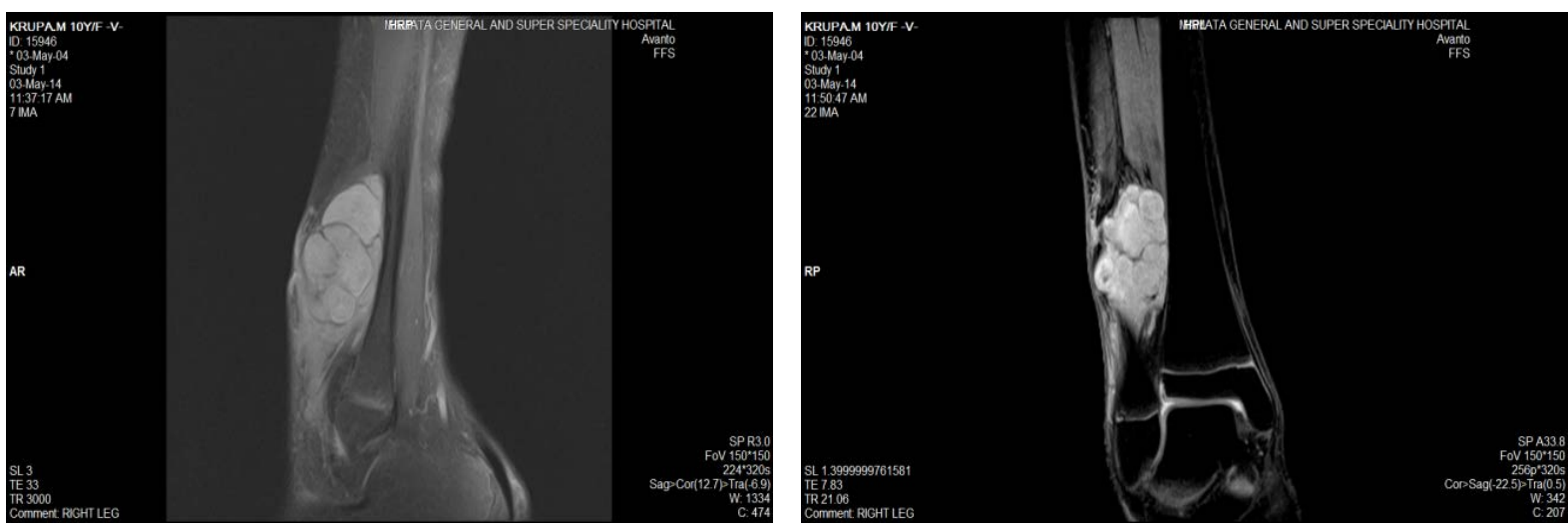

Figure 3. T1 and T2 images show multi-lobulated swelling over lower third of leg.

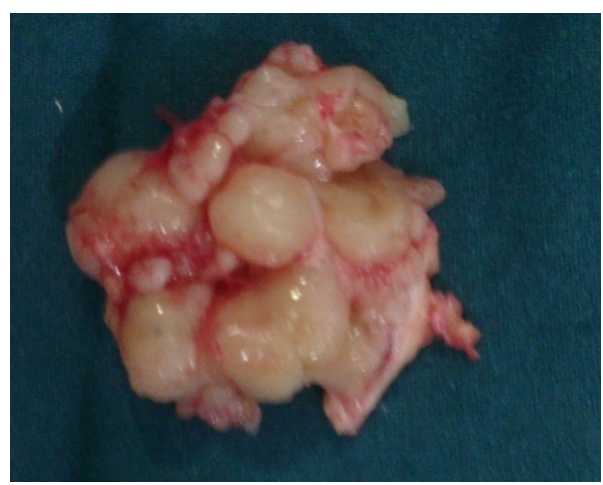

Figure 4. Gross specimen of resected tumour. 


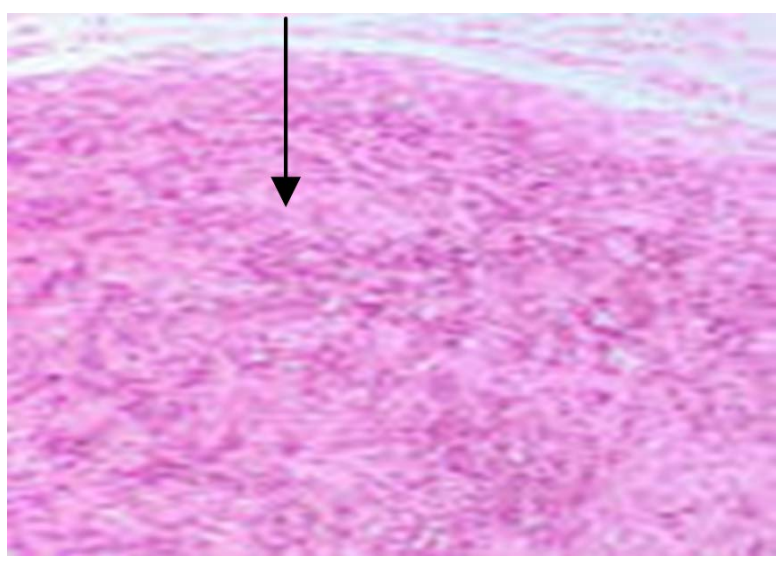

(a)

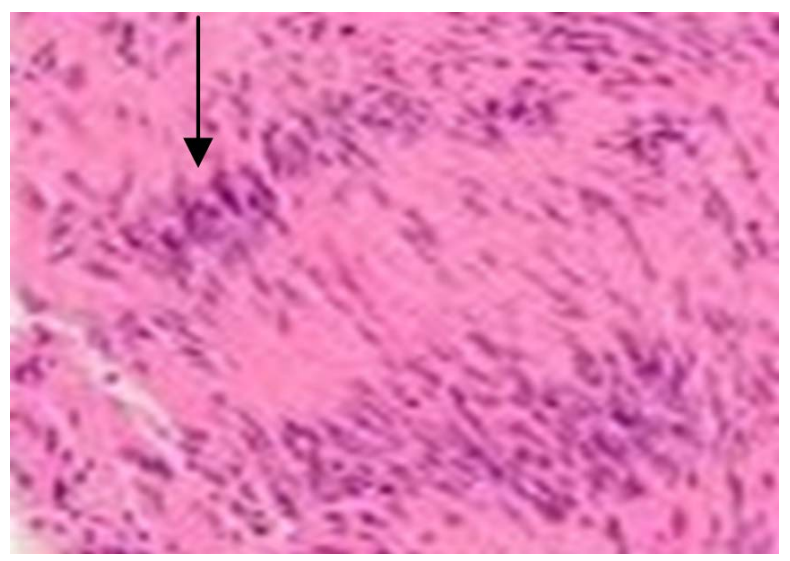

(b)

Figure 5. HPE showing Antoni A area composed of spindle shaped cells.

Schwannomas are derived from schwan cells of neuroectoderm. Their function is to form the myelin sheath of nerves in the peripheral nervous system, which insulates the nerve and facilitates the transmission of an impulse. Schwannomas is a benign encapsulated slow growing tumour [9] [10]. Unlike neurofibromatosis schwannomas do not traverse through the nerve but remain in the sheath lying on top of the nerve. They have a low risk of metastasis [11]. Schwannomas are most common in patients in second decade and have no gender or racial predilection [12]. They present with no symptoms, mild symptoms or severe symptoms mostly affecting nerves [13].

Malignant transformation of a schwannoma (neurilemoma) is an exceedingly rare event. Seven acceptable cases were found in the literature. Analysis of the nine cases of schwannoma with malignant transformation showed no sex predilection, but revealed a tumour differing significantly from conventional malignant peripheral nerve sheath tumours. Rather, the malignant component was commonly purely epithelioid [14] [15]. The prognosis for patients with schwannomas undergoing malignant change is poor. No significant signs of malignant transformation were seen in our case at follow-up of six months.

\section{Conclusion}

In summary, schwannomas are rare tumours. They very rarely affect the nerves of the lower limb, tumours of the nerve sheath. Resection of the lesion can relieve the pain. Benign tumour that mimics a lipoma or a malignant transformation that can be mistaken clinically for a liposarcoma has not been encountered in our follow-up of 6 months.

\section{Consent}

The patient's father has given his informed consent for the case report to be published.

\section{References}

[1] Russell, R.C.G., Williams, N.S. and Bulstrode, C.J.K. (2000) Bailey and Love’s Short Practice of Surgery. 23rd Edition, Arnold, London.

[2] Stout, A.P. (1949) Tumors of the Peripheral Nervous System. In: Atlas of Tumor Pathology, Armed Forces Institute of Pathology, Washington DC, Section 2.

[3] Takada, E., Ozaki, T., Kunisada, T., Harada, T. and Inoue, H. (2000) Giant Schwannoma of the Back. Archives of Orthopaedic and Trauma Surgery, 120, 467-469. http://dx.doi.org/10.1007/s004029900081

[4] Houshian, S. and Freud, K.G. (1999) Gigantic Benign Schwannoma in the Lateral Peroneal Nerve. American Journal of Surgery, 12, 41-42.

[5] Laurencin, C.T., Bain, M., Yue, J.J. and Glick, H. (1995) Schwannoma of the Superficial Peroneal Nerve Presenting as Web Space Pain. The Journal of Foot and Ankle Surgery, 34, 532-533.

http://dx.doi.org/10.1016/S1067-2516(09)80072-0 
[6] Thomas, G.P., Baco, A.M. and Rosenfeld, P. (2000) Schwannoma of the Superficial Peroneal Nerve. The Internet Journal of Orthopedic Surgery, 3, 12.

[7] Isobe, K., Shimizu, T., Akahane, T. and Kato, H. (2004) Imaging of Ancient Schwannoma. American Journal of Roentgenology, 183, 331-336. http://dx.doi.org/10.2214/ajr.183.2.1830331

[8] Bonar, S.F., Viglione, W., Schatz, J., Scolyer, R.A. and McCarthy, S.W. (2006) An Unusual Variant of Intraneural Ganglion of the Common Peroneal Nerve. Skeletal Radiology, 35, 165-171. http://dx.doi.org/10.1007/s00256-005-0031-y

[9] Joyce, M., Lating, A.J., Muller, H., Mofidi, A., Tansey, D., Connolly, C.E. and McCabe, J.P. (2002) Multiple Schwannomas of the Posterior Tibial. Nerve Foot Surgery, 8, 101-103. http://dx.doi.org/10.1046/j.1460-9584.2002.00290.x

[10] Liebau, C., Baltzer, A.W., Schneppenheim, M., Braunstein, S., Koch, H. and Merk, H. (2003) Isolated Peripheral Neurilemmoma Attached to the Tendon of the Flexor Digitorum Longus Muscle. Archives of Orthopaedic and Trauma Surgery, 123, 98-101.

[11] White, N.B. (1967) Neurilemmomas of the Extremities. Journal of Bone and Joint Surgery, 49A, 1605-1610.

[12] Hems, T.E., Burge, P.D. and Wilson, D.J. (1997) The Role of Magnetic Resonance Imaging in the Management of Peripheral Nerve Tumors. The Journal of Hand Surgery, 22, 57-60. http://dx.doi.org/10.1016/S0266-7681(97)80018-6

[13] Stull, M.A., Moser, R.P., Kransdorf, M.J., Bogumill, G.P. and Nelson, M.C. (1991) Magnetic Resonace Appearance of Peripheral Nerve Tumors. Skeletal Radiology, 20, 9-14. http://dx.doi.org/10.1007/BF00243714

[14] Schultz, E., Sapan, M.R., Mcheffey-Atkinson, B., Naidich, J.B. and Arlen, M. (1994) Case Report 872. “Ancient” Schwannoma (Degenerated Neurilemmoma). Skeletal Radiology, 23, 593-595.

[15] Murphey, M.D., Smith, W.S., Smith, S.E., Kransdorf, M.J. and Temple, H.T. (1999) From the Archives of the AFIP. Imaging of Musculoskeletal Neurogenic Tumors: Radiologic-Pathologic Correlation. Radiographics, 19, 1253-1280. http://dx.doi.org/10.1148/radiographics.19.5.g99se101253 
Scientific Research Publishing (SCIRP) is one of the largest Open Access journal publishers. It is currently publishing more than 200 open access, online, peer-reviewed journals covering a wide range of academic disciplines. SCIRP serves the worldwide academic communities and contributes to the progress and application of science with its publication.

Other selected journals from SCIRP are listed as below. Submit your manuscript to us via either submit@scirp.org or Online Submission Portal.
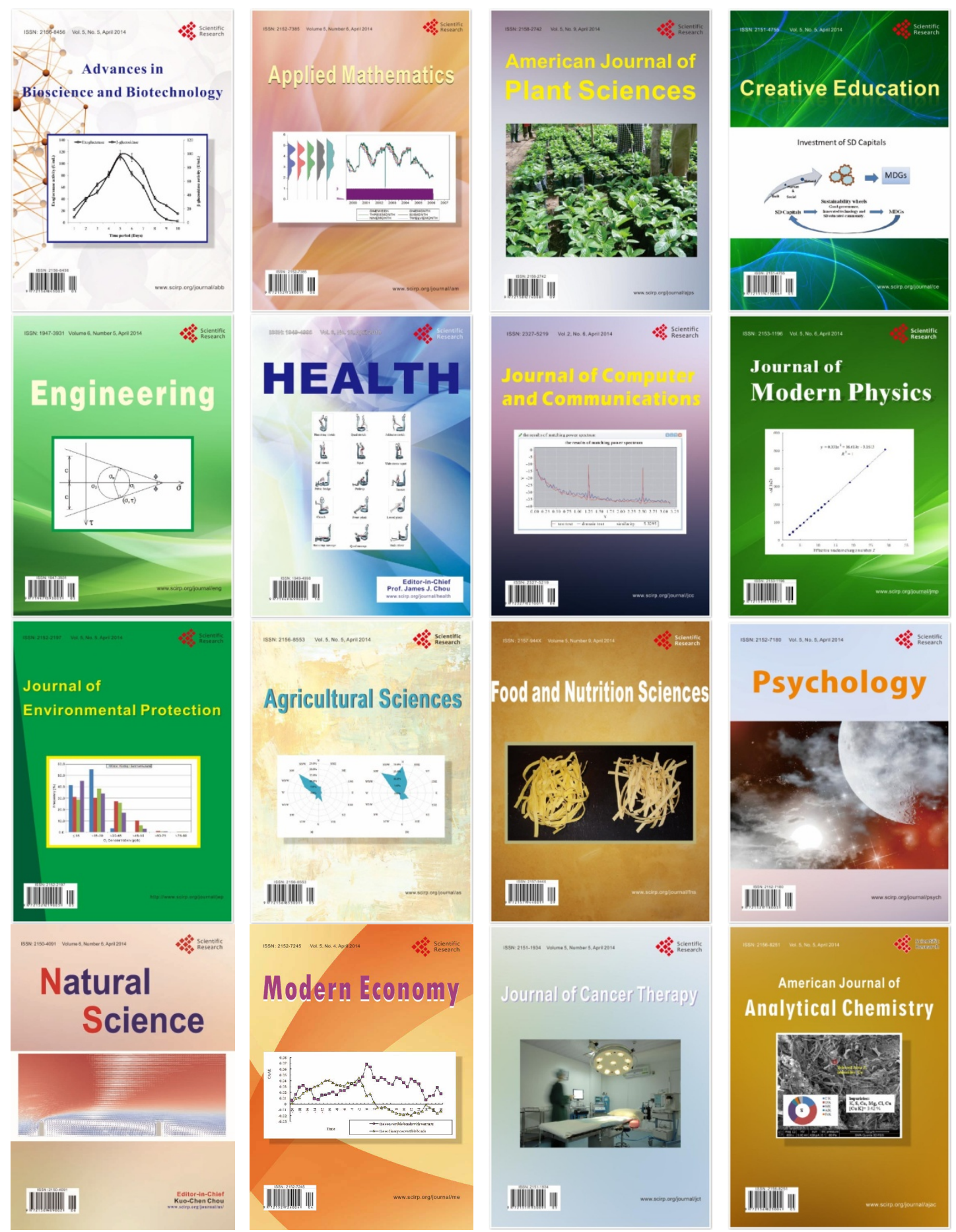